\title{
Queering "Pervert City"
}

\author{
Debra Shogan
}

|

Debra Shogan is a professor in the Faculty of Physical Education and Recreation at the University of Alberta. Her work is in cultural studies of leisure and sport. She may be contacted at debra.shogan@ualberta.ca.

I n 1997, junior hockey coach Graham James was sentenced to three-and-a-half years in prison for abusing Sheldon Kennedy and another unnamed player whom James coached as junior players. Sheldon Kennedy was well known as a National Hockey League (NHL) player and this, together with the fact that hockey is considered by some to be Canada's national pastime, created great interest in the incident not only among the people involved in the scandal but in the places where the abuse was reported to have happened. One of these places, Swift Current, Saskatchewan, received most of the media attention because it was here that James, Kennedy, and Kennedy's teammates achieved their greatest success, winning the Memorial Cup for junior hockey supremacy and producing a number of stars for the NHL.

While much can be written about this episode in Canadian sporting history, including how sexual abuse in sport emerged as an ethical issue worthy of attention, ${ }^{1}$ in this paper I am interested in how representations of the James scandal by the popular media relied on a dominant cultural story (Hall; Kincaid) about sexual abuse of children and youth in dysfunctional families. I focus on how newspaper representations constructed meaning about the events,

${ }^{1}$ While little attention was paid to this issue before, despite frequent concerns expressed by female athletes in relation to their male coaches, it took NHL player Sheldon Kennedy's story to produce policy, handbooks, websites, hot lines, skateathons, tv movies, and other ways of dealing with these issues. 
people, and place associated with the scandal from a pervasive cultural narrative that gave "form to ... our ways of seeing children, sexuality, and transgression" (Kincaid 5). Demonstrating how the scandal was represented in the media is not intended as a denial of events that took place in Swift Current. Rather, it is an attempt to make apparent how newspaper representations of these events invoked a dominant cultural story about sexual abuse in dysfunctional families and, in this particular case, represented Swift Current as a dysfunctional family, a complicit yet innocent bystander in the sexual abuse of junior hockey players coached by James.

Once the story broke that James had been charged with assaulting junior hockey players, and particularly once Sheldon Kennedy, by then an NHL player, came forward to talk publicly about what had happened, news media across North America became interested in Swift Current. The Globe and Mail, for example, described Swift Current this way:

To understand why the James affair has hit Swift Current so hard, you first need to understand how small the city is and how big the sport.

Swift Current is the sort of place where people are excited that Tommy Hunter is coming this month to perform ... It's the sort of place where people are still known by what church they belong to, where you could drive down the fiendishly cold main street last week and see a whole row of cars left running and unlocked

... In such a climate, those who play for the Broncos are local heroes who stand a chance of living the Canadian dream of playing in the NHL, feted guests of honour at fowl suppers, and community leaders with a stature far beyond their years. (Mitchell A6)

Swift Current was also described by the media as angry and betrayed (Brownridge, "Assault" A2); characterized as a town of deep shame (Gillis, "Sex Assaults" A1); and called "Pervert City" by one of my colleagues, when I indicated that that was where I was born. Swift Current was reduced simultaneously to a city of perversion and bucolic innocence: a place with "its heart broken, its shoulders slumping, every bone in its body aching as it searches within itself for answers" (Drinnan B1). As I explain, these contradictory 


\section{2 / Shogan}

representations can coexist within a cultural narrative about sexual abuse in dysfunctional families.

In what follows, I first read newspaper representations of Swift Current as a dysfunctional family through a familiar cultural story about sexual abuse that highlights notions of complicity, duplicity, and innocence. However, in order to confound representations of Swift Current as a place fixed by this cultural story, I intervene with my own understanding of this place. As a queer youth living in Swift Current in the 1950s and 1960s, I was often smitten by adults who were my mentors. By interjecting some of my experiences, I hope to disrupt the cultural story of Swift Current as a dysfunctional family, as well as open up notions of authority, innocence, and sexual abuse to other possibilities. I offer my experiences not to assert the truth of this place, thus applying a different but still singular set of meanings to Swift Current and the relationships of the people who live and have lived there (Scott; Sedgwick). Rather, this is a deconstructive move. Referring to writing about her experiences with the diagnosis and medical treatment of breast cancer, Eve Kosofsky Sedgwick indicates that "it's hard not to think of this ... experience as ... an adventure in applied deconstruction" (12). Sedgwick's experiences call into question neatly packaged oppositions between safety and danger, fear and hope, past and future, thought and act, and the natural and the technological and, in doing so, disrupt precise definitions of identity, gender, and sexuality $(12,13)$. Likewise, recounting some of my experiences of sexuality as a youth living in Swift Current, including my pursuit of my coach, has the potential to call into question oppositions between innocence and dysfunction, the normal and the perverted, and insiders and outsiders and, in so doing, disrupt the tidy stories told about sexual abuse of innocent youth in dysfunctional families (or places). I intend the intervention of my experiences to be a queer reading of this place called "pervert city," where queer suggests that "meanings ... can be at loose ends with each other" (Sedgwick 6). In turn, I hope to show that Swift Current exceeds its representations as a healthy, family town and its representations as a town of perversion or dysfunction.

But before proceeding with the popular media and my own reading of Swift Current, I present a brief chronology of the scandal involving James and Kennedy. 


\section{The Scandal}

Graham James began his coaching career in Manitoba in the late 1970s and by the beginning of the 1980s he had become a Junior A hockey coach. He first encountered Sheldon Kennedy at a hockey school in 1982 when Kennedy was thirteen years old. In 1984, James recruited Kennedy to his Winnipeg team and, when this team was moved to Moose Jaw, James arranged to have Kennedy move with him. According to Kennedy, James began sexual contact with him not long after his arrival in Winnipeg. While in Moose Jaw, the expectation that Kennedy would go to James's apartment every Tuesday and Thursday began and continued until Kennedy was nineteen years old.

James was dismissed from the Moose Jaw team for suspected improprieties that were only revealed once the abuse story broke. He moved Kennedy with him to Winnipeg for a short time and then in 1986 he became the head coach of the Swift Current Broncos. He ensured that Kennedy joined him there. In 1986, a bus accident killed four of the Bronco players and James was credited with helping the surviving players through the ordeal (Robinson 160). In 1989, the Swift Current Broncos won the Memorial Cup with the most successful record ever in the Canadian Hockey League. Sheldon Kennedy had outstanding seasons both in 1988 and in 1989 and was named to the national junior team in 1988 .

Kennedy was drafted by the Detroit Red Wings in 1989 and acquired a reputation as someone emotionally out of control. He was convicted of reckless driving and charged with drug possession, and he was traded a number of times. Meanwhile in Swift Current, James continued his success as a winning coach and gained popularity as a colorful personality. However, at the end of the 1993-94 season, James's contract was not renewed. He subsequently appeared in Calgary where he became part-owner, general manager, and head coach of the Calgary Hitmen (Robinson 164). In 1997, while Kennedy was a player for the Boston Bruins, he went public with his story.

In 1997, Graham James was sentenced to three-and-a-half years in prison. He was released from prison in July 2000 and, to the consternation of the Canadian Hockey Association and of many in the sporting public, James became a coach with the Spanish national team. 


\section{Reading Representations of Swift Current through Stories of Sexual Abuse}

Experts in psychology, social work, and other human sciences have played a prominent role in producing a story about sexual abuse in dysfunctional families that has become familiar in Western culture (see Armstrong; Crewsdon; La Fontaine; Miller; Rush). This is a story of sexual abuse in a "'family system' gone wrong [where] each family member own[s] a piece of the problem" (Dinsmore 15). According to Pat Gilmartin, family pathology is not regarded as an "idiosyncratic behavior of a single member of that unit; rather, the family system is implicated as causing and perpetuating whatever problem that exists" (82). Family members are all implicated in the abuse as victims, perpetrators, gullible innocents, or complicit third parties (Butler).

As I have said, newspaper reporters' attempts to understand what happened in Swift Current were cast in terms of the familiar cultural story about sexual abuse in dysfunctional families. Official City information sources and outside media represent Swift Current as valuing families. The city website, for example, indicates that "Swift Current is a city of families and friends. Our continuing efforts to maintain a high quality of life and opportunity for our neighbours is only rivalled by our desire to welcome new families to Swift Current and make new friends" ("Swift Current"). Swift Current not only values family, it is a family, according to some. For example, Joe Arling, a hotel owner and member of the board of directors of the Broncos, was reported in 1997 to say:

This is a community with very strong morals and beliefs. It has very strong family values and in a way, it's a family itself. To me, what Graham did was a violation of trust and position, just like priests and teachers have abused their positions. Hockey just happened to be the venue, in this case. But like anywhere, there'll be significant hurt here. No one would have expected it to happen in this community. (Qtd. in Gillis, "Hockeytown" H2)

Swift Current is a family, but a dysfunctional one. Moreover, people in Swift Current were represented as recognizing the dysfunction of the community: “One thing's certain, this farming, railway and oil community - a well-spring of dedicated, sometimes brilliant hockey players - will never feel the same about itself. Or its and Canada's favourite game" (Gillis, "James Incident" A2). 
As a dysfunctional family, Swift Current was represented as complicit in the sexual abuse of the junior hockey players who lived there. In some accounts James was cast as a member of the dysfunctional family that made possible the abuse of Kennedy and other junior hockey players: "while preying on boys for his confessed sexual gratification, James could not operate alone. He had help and lots of it. Passive, blind, hopelessly naive help from those who most trusted the junior hockey coach: parents, billets, league and team administrators, and teammates" (Ormsby D3).

Many reporters and some residents of the city were reported to have thought it was impossible that no one knew that the sexual abuse was happening in Swift Current. Two residents of the Saskatchewan city were quoted as saying: "'I just can't imagine how somebody could live with these players and not try to figure out why they were spending so much time with the coach"”; "'What do you mean nobody knew? I'm sure people knew, but they just didn't do anything"' (qtd. in Gillis, "Sex Assaults" A4). Another account went so far as to surmise that the team organization refused therapy for team players after the tragic bus accident in 1986 left four players dead, because they were afraid that "the terrible truth about James' sexual shenanigans [would] surface" (McConachie B1). In these representations, Swift Current assumed the role of the mother within the dysfunctional family: the "invisible third partner," "colluding" in the sexual interaction between the abuser and the child or abandoning the child to the abuser (see Butler 102,113). It is assumed in this conventional story about sexual abuse that abuse would not have occurred if the mother, in this case Swift Current, had not created a particular emotional climate through "commission and omission" (Butler 114).

Central to the story of sexual abuse in dysfunctional families is the gullibility of at least some family members. Reporters represented Swift Current as innocently caught up in and bewildered by the events:

Meanwhile, the citizens of Swift Current will never understand how or why all of them came to be victims, too. But that's what happens when sexual abuse, society's dirty little secret, rears its ugly head in your community. There are good people in Swift Current, good people, salt-of-theearth people, who are torturing themselves, trying to 


\section{6 / Shogan}

understand what it is that went on behind closed doors in their community and why they weren't able to recognize the signs. (Drinnan B1)

The trainer of the Broncos was reported to have said, "'I've been lying awake every night thinking, "Did I miss something? Were there signs I didn't see?" But there just weren't any hints"' (qtd. in Gillis, "James Incident" A2).

The familiar cultural story of sexual abuse in dysfunctional families includes accounts of loyalty of members to the abuser (see esp. Butler 121). The loyalty of some Swift Current residents to James was central to some media depictions. When faced with the allegations about James, team president, John Rittinger, was reported to have said that, "'the Graham I know was always a pleasant, humorous fellow. It's impossible for me to believe that a man of his intelligence would get involved in something like this. I couldn't be more devastated by this if Graham had died. I couldn't feel worse by this if it was my own family"' (qtd. in Todd G2). There were many letters of support submitted at James's trial by former players and administrators of the Broncos' organization (Robinson 168). This loyalty to James was interpreted as just another indication of the dysfunction of the city.

Gilmartin indicates that social-psychological explanations of sexual abuse of children in families "keeps the focus on individual families as the problem and ignores the societal power imbalances which many families mimic" (87). Much of the reporting about the James case, while differing about whether Swift Current was complicit, innocent, or both, nevertheless represented this place as an aberration among Canadian cities. Administrators of hockey sport governing bodies were also keen to make the point that what happened in Swift Current was not representative of hockey culture. Hockey authorities were quick to represent the James case as an isolated incident and not reflective of junior hockey (see Todd G2). However, accounts such as Laura Robinson's in Crossing the Line: Violence and Sexual Assault in Canada's National Sport document how abuse of and by hockey players may be central to hockey culture. Robinson argues that abuse in hockey is institutionalized and that abuse takes many forms, including pressure on young players to excel and conform, hazing rituals, and sexual abuse. 
A common representation by the media of the James affair was that James duped Swift Current by fooling them with his charm and knowledge of hockey.

This was a man of contradictions ... James was a pillar of the community. He was a role model. He was on the Broncos' bus that ugly night 10 years ago and he helped the community mend its broken heart, the same heart he would smash to smithereens. He picked that team up by the skatelaces and took it to a Memorial Cup championship just three years later. It was a miracle that put Swift Current on the map. Now it turns out he was the devil in disguise. (Drinnan B1)

In this representation, James is not one of the family. He is an outsider, described by one of the players' billets as ““'an import to the community"” (qtd. in Gillis, "James Incident" A2). The mayor of the city at the time also distanced the community from James by indicating that, "'this is an isolated event by perhaps a deranged person. Certainly, it doesn't reflect the community"' (qtd. in Vanstone A1).

While, for the most part, the mainstream media did not link the charges of abuse to James's homosexuality, they did portray him as "a very private man, rarely seen socially" (Brownridge, "Feeling" A1). The Alberta Report, a right-wing, Christian fundamentalist news weekly accused other media of downplaying James's homosexuality and ignoring what they portrayed as "the known link between homosexuality and pedophilia" (Sillars 34). Albert Howlett, a Bronco supporter, shared the indignation: "'You pretty near have to put him down near the lowest class of person you can be. What he did with those boys was terrible"" (qtd. in Vanstone A1).

Many in the city were reported to have known about James's homosexuality, with the effect that reporters did not take seriously the representation of the city by one of its citizens as a naïve Biblebelt town (Mitchell A6). A former Bronco director was reported to have said that: "'There were rumors about Graham's sexual orientation, but never any suggestion he was sexually abusing players ... Innuendo, suspicion and rumour was all there was, and until someone comes forward, there's really nothing you can do. If you decided to end a coaching contract on something like that, human rights would be all over you"” (qtd. in Gillis, “James Incident” A2). 


\section{8 / Shogan}

In another report, the director was attributed with the following remark: "Some of the club's inner circle suspected that Mr. James was a homosexual but they were broad-minded enough not to assume that a gay man also had a taste for the youths under his control" (Mitchell A6). That the "homophobic world of junior hockey" (Todd G2) would be so open to homosexuality stretched the limits of credulity for most reporters. One asked rhetorically, "Could it be that as long as you're winning and developing NHL stars, people look the other way? Could it be that James would have been found out long ago if he was a losing coach?" (Todd G2).

A flurry of articles identifying other 'homosexual' coaches who had been 'known' to prey on players (see Houston / Campbell Al; Spector, "Scars" A1; Stock / Crowley A1) belied the representation of James as an exception. Many of these coaches were dead and not in a position to defend themselves. Most attention was paid to Brian Shaw, former coach, general manager, and owner of the Edmonton Oil Kings and Portland Winter Hawks. The Edmonton Journal also carried a front-page story with pictures about Peter Spear, who died in 1988, and who allegedly abused at least one of his players (Spector, "Scars" A1). None of these accounts of homosexuality in hockey, including the disingenuous reference to looking the other way, acknowledged what many of the reporters must have witnessed: the homoeroticism of the locker room. As Brian Pronger indicates, "locker rooms are places where orthodox men like to hang around naked, talking and joking with each other" (76). In response to the revelation that James regularly showered with his players after practices, Western Hockey League coach, Mike Babcock, reported that, in the aftermath of the scandal, he and his assistant coaches had talked about whether they should continue to shower with players when the team was on the road ("Stars" E2). If there were indications of James's sexual interest in Bronco players, they may have been indistinguishable from homoerotic interactions taken for granted on male sporting teams.

The story about sexual abuse in families and family-like settings is unable to account for homoerotic behavior on male athletic teams nor can it contain Kennedy's or James's understanding of what happened between them. When asked about his willingness to go to where James was coaching after the first sexual encounter, Kennedy responded, " Well yeah ... I was scared sh_less ... I knew right 
after, but there was nothing I could do because I wanted to play"” ("Player's Self-Esteem" D10). Jimmy Devellano, who drafted Kennedy from Swift Current, was one of many people surprised by Kennedy's accusations because, according to Devellano, Kennedy "“always talked about Graham so sincerely"” (Simmons B1). A former Bronco vice-president said he was told that James was "doing it" with Kennedy: "II figured that if they were doing it, they were doing it with consent"' (qtd. in Vanstone A5). Kennedy later said that he believed that James was in love with him. He also indicated that James knew what he was doing and "'he should have known that it wasn't accepted, because I had mentioned many times that I hated it"' (qtd. in Board D1). Kennedy said that he could not tell anybody because "I was so scared to come out and admit it happened to me. I was scared to say I was with another man"” ("Learning" A2). James commented after his trial that he realized that Kennedy was not comfortable with the sex but he tolerated it because, "'he legitimately cared. Not about THAT (the sex) obviously. He cared. He knew I was lonely and you know, that sort of registered as desperation"" (qtd. in Spector, "Kennedy Disclosure" D6). When asked in an interview from prison whether he realized that what he was doing was wrong, James responded, “"when you're attracted to somebody, you're blinded, and you try to justify things, and you figure if you can do enough for somebody then somehow that makes up for it"” (qtd. in "“Caring"” K2); "II suppose you don't think these things ... will be brought out into the general public. It's like anybody's sex life - it goes out in the general public [and] it doesn't look too flattering"” (qtd. in "James Says" E2).

Irrespective of the homoeroticism of the locker room or what James or Kennedy had to say, media representations of Swift Current and the people who live there sustained an understanding of sexual abuse consistent with conventional stories of abuse in dysfunctional families. This is a story of innocence, collusion, duplicity, and gullibility. Yet Swift Current and the events that took place there are open for other readings.

\section{Another Reading of Swift Current}

As it turns out, many of the places where the events that implicated James and Kennedy occurred were places I had inhabited under different conditions, twenty years earlier. During high school, I lived 
in a house on Jubilee Drive in the northeast side of the city. This house was later sold to Colleen and Frank McBean who billeted Bronco players through the 1990s. Kennedy was one of these players.

Kennedy would have left the side door into the car park every Tuesday and Thursday evening to go to James's house. Was his room the southeast bedroom where I had spent so much time as a fifteen year old thinking about my first girlfriend? This girlfriend was eighteen, and under today's laws would be considered an adult. As I found out later, she was two-timing me with her female college coach.

Many reporters have wondered how the people of Swift Current, especially those billeting players, could not have known that a player was sexually involved with the coach. They surmised that people must have known or were too simple or naive to have guessed. I often went to my basketball coach's apartment, usually unannounced, hoping to seduce her. I was oblivious to whether the neighbors knew. My coach's careful closing of the curtains upon my arrival was reason for me to be hopeful of what might happen but, as I think about it now, she was likely very aware that some would think that a player should not be in her coach's home unsupervised at night. Only she and I were aware that the seventeen-year-old girl was pursuing the twenty-five-year-old coach. Applied to me, the story of innocence and dysfunction would have shrunk a "smart and active older adolescent ... into a child, a generic "essence-of-child"' (Kincaid 31).

My mother did not ask me questions about spending time with my coach. Instead, my mother often helped me buy chocolate bars for her. Nor did she have much to say about the black eye my coach accidentally gave me when we were wrestling in the locker room. This black eye would have been very difficult for my coach to explain if someone had chosen to cast my relationship with her as inappropriate. In some accounts, James was accused of threatening Kennedy with a gun. James had this to say about the gun: " "There was a gun in a sense of a Cluseau-Kato type thing. He'd chase me until I could find something to stop him, and vice versa. Then we'd laugh about it. That's all there was to it"' (qtd. in Spector, "Kennedy Disclosure" D6).

Was my mother complicit in my sexual encounters with girls my own age? Was she implicated in my active pursuit of a young woman in authority who, arguably, in sexual terms was more innocent 
than I was? My mother told me much later that she did not have the language to broach my sexuality with me. According to the 'familiar story,' this inability to talk about what may have appeared as an unusual relationship with my coach is evidence of the dysfunction of my family. As the titles of books telling this story reflect, silence is considered to be central to dysfunction (Butler; Miller; Rush). I had a sense then, however, that by helping me buy small presents for my coach my mother communicated her tacit approval of me.

Agonizing about what the adults should or should not have known or done cannot account for the complications of people's lives. Colleen and Frank McBean, for example, began billeting Bronco players, including Kennedy, after losing two of their sons in a tragic vehicle accident. Whether and how this tragic event affected the decisions that were made in relation to the boys in their care cannot be captured by implying that they somehow colluded in what was later understood as Kennedy's abuse. They may have been unable to make explicit what was later construed as a terrible abuse of authority by a coach whose 'victim' left his home twice a week, every week, for four years to visit the coach.

Swift Current and its people cannot be captured by stories about dysfunction and innocence, nor can the relationships between the adults and youth who live and have lived there. Many of my memories of living as a child and teenager in Swift Current reproduce this as a time and place marked by innocence, exuberance, creativity, and fun. But I know that these memories make sense to me in contrast to the heaviness that often accompanies adulthood. With little effort, however, I can also remember the stranger in the car who persisted in trying to give me a ride home when I was five; the woman who did some sewing for my mother who was found dead in the Swift Current creek; the rape of one of my sister's friends; the way the kids at school treated the children of one family because they were poor and Arab and lived in the valley; the man who turned out to be a woman who drove the "honey wagon" (the name given for the horse drawn wagon that carried the excrement from the outdoor toilets used by the people in the valley); children throwing rocks at the man with cerebral palsy who dared to try to walk in his neighborhood; what I now understand to be the racism that invaded the speech of the adults around me; or the awesome wrath of one of my teachers when I was ten because I persisted in playing hockey with the boys. 


\section{2 / Shogan}

Years later, my mother apologized for not doing something more to ease what she thought must have been a horrible time for me living in Swift Current. But it was not a horrible time. Rather it was then and there that I found other girls like me and we engaged in sexual lives not remotely imagined in representations of Swift Current as a quaint, quiet family town or as a dysfunctional city complicit in the sexual abuse of its young people. Still, I am surprised by the apparent casualness to homosexuality expressed by at least some in the community during the James scandal. In the 1960 s, I would have sworn that, except for those of us engaged in these thrilling subterranean practices, no one had a clue that people did these things. But at least some people did know about these activities when I lived there, including my mother, as did some during the time James and Kennedy were living in Swift Current. Yet, dominant cultural stories about families, sexuality, relationships, and innocence still circulate, making it difficult to understand events, people, and places in anything but the terms of these stories. What has changed, however, is that queer stories are being told about the relationships between people that occurred in these places. These queer stories situate dysfunction not in individuals or places but in a cultural story that simplifies complicated lives. The dysfunction of the cultural story is that it permits only two main roles, "monster and victim ... along with supporting parts for police, judges, juries, therapists, parents, friends, journalists, and lawyers" (Kincaid 30).

I want to emphasize that I am not saying that my experiences in Swift Current prove somehow that Kennedy was not traumatized by the sexual encounters he had with James. Rather, I want to show that the stories about dysfunctional families and the innocence of youth are too simple to capture the complexity of relationships, events, and people. In their simplicity, they have the effect of fixing what we can know about a place, the people who live there, and certain events in a way that is "intolerant and relentless" (Kincaid 30). My queer reading of "pervert city" renders the meaning of this place and of the events that happened there a little less tidy.

\section{Works Cited}

Armstrong, Louise. Home Front: Notes from the Family War Zone. New York: McGraw-Hill, 1984. 
Board, Mike. "Kennedy Describes His Life as a Lonely Hell." Gazette [Montreal] 7 Jan. 1997: D1.

Brownridge, David. “A Feeling of Betrayal." Leader Post [Regina] 4 Jan. 1997: A1.

. “Assault Charges Stun Swift Current." Star Phoenix [Saskatoon] 4 Jan. 1997: A2.

Butler, Sandra. Conspiracy of Silence. Volcano, CA: Volcano, 1985.

“'Caring' Coach Tells His Story.” Edmonton Sun 7 Jan. 1997: 12.

Crewsdon, John. By Silence Betrayed: Sexual Abuse of Children in America. New York: Little Brown, 1988.

Dinsmore, Christine. From Surviving to Thriving: Incest, Feminism, and Recovery. New York: State University of New York Press, 1991.

Drinnan, Gregg. "Swift Current Tries to Heal Its Wounds." Leader Post [Regina] 9 Jan 1997: B1.

Gillis, Charlie. "Hockeytown, Canada Searches Its Soul." Edmonton Journal 11 Jan. 1997: H1-H2.

. "James Incident Steals City of Its Innocence." Star Phoenix [Saskatoon] 14 Jan. 1997: A2.

"Sex Assaults Shock Prairie Town." Gazette [Montreal] 12 Jan. 1997: A1, A4.

Gilmartin, Pat. Rape, Incest, and Child Sexual Abuse. New York: Garland, 1994.

Hall, Stuart, ed. Representation: Cultural Representations and Signifying Practices. London: Open University, 1997.

Houston, William and Neil Campbell. "Ex-WHL Boss Abused Players." Globe and Mail [Toronto] 9 Jan. 1997: A1.

“James Says He Feels Betrayed by Kennedy." Vancouver Sun 8 Jan. 1997: E2.

Kincaid, James R. Erotic Innocence: The Culture of Child Molesting.

Durham: Duke University Press, 1998.

Fontaine, Jean. Child Sexual Abuse. Cambridge, UK: Polity, 1990.

"Learning to Live Again." Leader Post [Regina] 7 Jan. 1997: A1, A12.

McConachie, Doug. "Independent Investigation Needed by WHL." Star Phoenix [Saskatoon] 15 Jan. 1997: B1

Miller, Alice. Thou Shalt Not Be Aware. New York: Farrar, Straus \& Giroux, 1983. 


\section{4 / Shogan}

Mitchell, Alana. "Swift Current's Hockey Pride Left in Tatters." Globe and Mail [Toronto] 14 Jan. 1997: A6.

Ormsby, Mary. "Be Vigilant to Protect Vulnerable Youngsters."

Toronto Star 4 Jan. 1997: D3.

"Player's Self-Esteem Sank after Years of Abuse." Vancouver Sun 7 Jan. 1997: D10.

Pronger, Brian. The Arena of Masculinity: Sports, Homosexuality and the Meaning of Sex. Toronto: University of Toronto Press, 1992.

Robinson, Laura. Crossing the Line: Violence and Sexual Assault in

Canada's National Sport. Toronto: McClelland and Stewart, 1998.

Rush, Florence. The Best Kept Secret: Sexual Abuse of Children. Englewood Cliffs, NJ: Prentice-Hall, 1980.

Scott, Joan. "Experience." Feminists Theorize the Political. Ed. Judith Butler and Joan Scott. New York: Routledge, 1992. 22 40.

Sedgwick, Eve Kosofsky. Tendencies. Durham: Duke University Press, 1993.

Sillars, Les. "Hockey Pays the Price for Gay Tolerance." Alberta Report 20 Jan. 1997: 30-34.

Simmons, Steve. "Many Tried to Help a Troubled Kennedy." Star Phoenix [Saskatoon] 8 Jan. 1997: B1.

Spector, Mark. "Scars That Last a Lifetime." Edmonton Journal 9 Jan. 1997: A1, A9.

" "Kennedy Disclosure a Betrayal: James." Star Phoenix [Saskatoon] 9 Jan. 1997: D6.

"Stars Looking to Shine over Hockey Scandal." Leader Post [Regina] 22 Jan. 1997: E2.

Stock, Curtis and Norm Cowley. "The Saddest Power Play." Edmonton Journal 7 Jan. 1997: A12.

"Swift Current Community Information." 1 Dec. $2001<$ http:// www.city.swift-current.sk.ca/info/index/htm>.

Todd, Jack. "Junior Hockey Looks Other Way." Gazette [Montreal] 4 Jan. 1997: G2.

Vanstone, Rob. "Shadow over a Hockey Town." Leader Post [Regina] 11 Jan. 1997: A1. 